\title{
Perancangan Sistem Informasi Pemesanan Paket Pernikahan Berbasis Web Pada Diamond Wedding Jakarta
}

\author{
Fauzi Rizaldi $^{1)}$, Sita Anggraeni' ${ }^{2}{ }^{*}$, Ipin Sugiyarto ${ }^{3)}$ \\ ${ }^{122) 3)}$ Sekolah Tinggi Manajemen Informatika dan Komputer Nusa Mandiri \\ ${ }^{*}$ Correspondence Author: sita.sia@ @usamandiri.ac.id, Jakarta, Indonesia \\ DOI: https://doi.org/10.37012/jtik.v7i1.497
}

\begin{abstract}
Abstrak
Wedding Organizer merupakan organisasi penyedia jasa yang berfungsi membantu calon pengantin dan keluarga dalam perencanaan dan supervisi pelaksanaan rangkaian acara pesta pernikahan. Acara pesta pernikahan diadakan sesuai dengan jadwal dan budget yang telah ditetapkan. Adanya beberapa kendala seperti pengisian data, proses transaksi penyewaan, pencarian dan pembuatan laporan yang membutuhkan waktu yang cukup lama dan tidak efisien. Bahkan penyimpanan data yang tidak optimal karena masih menggunakan pembukuan transaksi secara manual. Perancangan program pernikahan pada Diamond Wedding memanfaatkan Teknologi Informasi berbasis web dengan tujuan untuk memperluas area promosi dan penjualan paket pernikahan dan mempermudah proses pemesanannya. Perancangan Program Berbasis Web ini merupakan solusi yang terbaik untuk memecahkan permasalahan-permasalahan yang ada diperusahaan tersebut. Tujuannya agar dapat tercapai suatu kegiatan yang efektif dan efisien, guna menunjang aktifitas pada perusahaan. Program Pemesanan Paket Pernikahan pada Diamond Wedding dapat membantu calon pengantin dalam mempersiapkan acara pernikahan secara real time online karena sudah menggunakan website dalam pemesanannya. Program pemesanan paket pernikahan ini dilengkapi dengan adanya from transaksi dan konsultasi. Fasilitas tersebut mempermudah customer dalam melakukan proses transaksi pemesanan, sehingga tidak akan menyita waktu yang lama.
\end{abstract}

Kata Kunci: Sistem Informasi, Paket Pernikahan, Web

\begin{abstract}
Wedding Organizer is a service provider organization whose function is to assist the bride and groom and their families in planning and supervising wedding ceremony events. Weddings are held according to a predetermined schedule and budget. There are several obstacles, such as data entry, rental transaction processing, search and report generation which takes a long time and is inefficient. Even data storage is not optimal because it still uses manual transaction bookkeeping. The design of the wedding program at Diamond Wedding utilizes web-based information technology with the aim of expanding the area of promotion and sale of wedding packages and simplifying the ordering process. This Web-Based Program Design is the best solution to solve the problems that exist in the company. The goal is to achieve an activity that is effective and efficient, in order to support the activities of the company. The Diamond Wedding Package Ordering Program can help the bride and groom prepare for their wedding in real time online because they already use the website in their order. This wedding package booking program is equipped with the existence of transactions and consultations. This facility makes it easier for customers to process the order transaction, so it won't take a long time.
\end{abstract}

Keywords: Information Systems, Wedding Packages, Web

\section{PENDAHULUAN}

Diamond Wedding adalah perusahaan yang sudah berdiri sejak tahun 1991, bergerak dibidang "One Stop Wedding Service", dimana seluruh kebutuhan para calon pengantin untuk hari pernikahannya disediakan secara lengkap. Setiap orang punya sebuah impian tentang acara pernikahan yang sempurna. Namun, pesta pernikahan yang sempurna 
membutuhkan persiapan yang cukup panjang, dan dana yang tidak sedikit. Rutinitas yang sangat tinggi menyebabkan tidak ada waktu untuk mempersiapkan segala sesuatunya sendiri. Khususnya bagi mereka yang tinggal di kota metropolitan yang mempunyai tingkat kesibukan yang tinggi. Hanya sedikit waktu yang tersisa untuk keperluan pribadi seperti mempersiapkan pernikahan. Oleh karena itu diperlukan sistem informasi yang dapat membantu memudahkan user dalam mengelola data yang di perlukan. Dengan adanya sistem informasi, maka pekerjaan yang ada dapat diselesaikan secara cepat, tepat dan akurat. Salah satu industri yang berkembang adalah sanggar yang menyediakan jasa untuk acara pernikahan seperti paket-paket pernikahan, pakaian dan rias pengantin, cattering, souvernir, model dekorasi dan lainnya.

Sistem informasi pemesanan membuat wedding organizer dapat memanfaatkan informasi technology berbasis web, dengan tujuan untuk memperluas area promosi dan penjualan paket pernikahan dan mempermudah proses pemesanan. Program pemesanan wedding organizer menggunakan tool pemrograman PHP dan MySQL. Sistem informasi pemsanan wedding organizer ini menyediakan tempat untuk para pihak Wedding Organizer menginformasikan paket-paket pernikahan yang akan mereka sewakan. Sistem ini juga menyediakan tempat bagi para penyewa untuk melakukan pemesanan paket pernikahan tanpa harus datang ke lokasi Wedding Organizer. Sistem informasi ini dilengkapi dengan gambar atau foto, sehingga penyewa dapat mengetahui seperti apa contoh hasil dari resepsiresepsi yang pernah diselenggarakan. Wedding organizer adalah layanan personal yang mengoperasikan karyanya membantu calon pengantin wanita dan keluarga berencana dan mengawasi pelaksanaan acara rangkaian pesta pernikahan sesuai schedule dan budget yang telah ditetapkan.

Kemajuan teknologi internet dapat mempermudah konsumen dalam mengakses situs-situs yang dibutuhkan oleh konsumen, menghemat waktu dan tenaga dalam melakukan perbandingan. Oleh karena itu dengan berkembangnya kemajuan teknologi ini, maka perlu adanya pembuatan sistem informasi pemesanan paket pernikahan berbasis web di Diamond Wedding Jakarta. Informasi tentang program pernikahan berbasis web yang dapat diakses oleh semua masyarakat melalui internet memberikan ide untuk pembuatan Sistem Informasi Pemesanan Paket Pernikahan Berbasis web pada Diamond Wedding Jakarta.

\section{METODE}

Dalam pembuatan penelitian ini, digunakan metode waterfall dalam pengembangan perangkat lunaknya. Metode pengumpulan data yang dipergunakan untuk mendapatkan 
keterangan-keterangan guna memenuhi kebutuhan dalam penyusunan penelitian ini adalah dengan observasi dan wawancara.

Pada sistem Diamond Wedding begitu banyak masyarakat yang ingin mendapatkan informasi lebih tentang pemesanan paket pernikahan sehingga mengharuskan masyarakat untuk datang langsung ke tempat. Oleh sebab itu muncul ide untuk membuat sebuah halaman web yang akan memudahkan para konsumen untuk memperoleh informasi tentang jasa pernikahan dalam melakukan transaksi secara online. Berikut ini spesifikasi kebutuhan (system requirement) pada Diamond Wedding yaitu :

Halaman Customer:

A1. Customer dapat melihat melihat isi dari paket-paket pernikahan yang ditawarkan.

A2. Customer dapat melakukan konsultasi sebelum memilih paket pernikahan.

A3. Customer dapat melakukan order atau pemesanan.

A4. Customer melakukan pembayaran dan menerima bukti pembayaran.

Halaman Pengunjung :

B1. Pengunjung dapat melihat website Diamond Wedding.

B2. Pengunjung dapat melakukan pendaftaran sebagai member.

B3. Pengunjung dapat melihat pilihat paket dan gallery poto paket pernikahan.

Halaman Admin :

C1. Admin mengelola data Kategori

C2. Admin mengelola data Galery

C3. Admin mengelola data Paket Pernikahan

C4. Admin mengelola data Buffet

C5. Admin mengelola data Testimoni

C6. Admin mengelola data Konsultasi

C7. Admin mengelola data Transaksi dan Konfirmasi Pembayaran

ERD (Entity Relationship Diagram) berfungsi untuk menggambarkan model basis data yang akan dipakai. Model basis data yang digunakan adalah basis data relasional, Berikut adalah bentuk ERD dari perancangan sistem yang dibuat: 


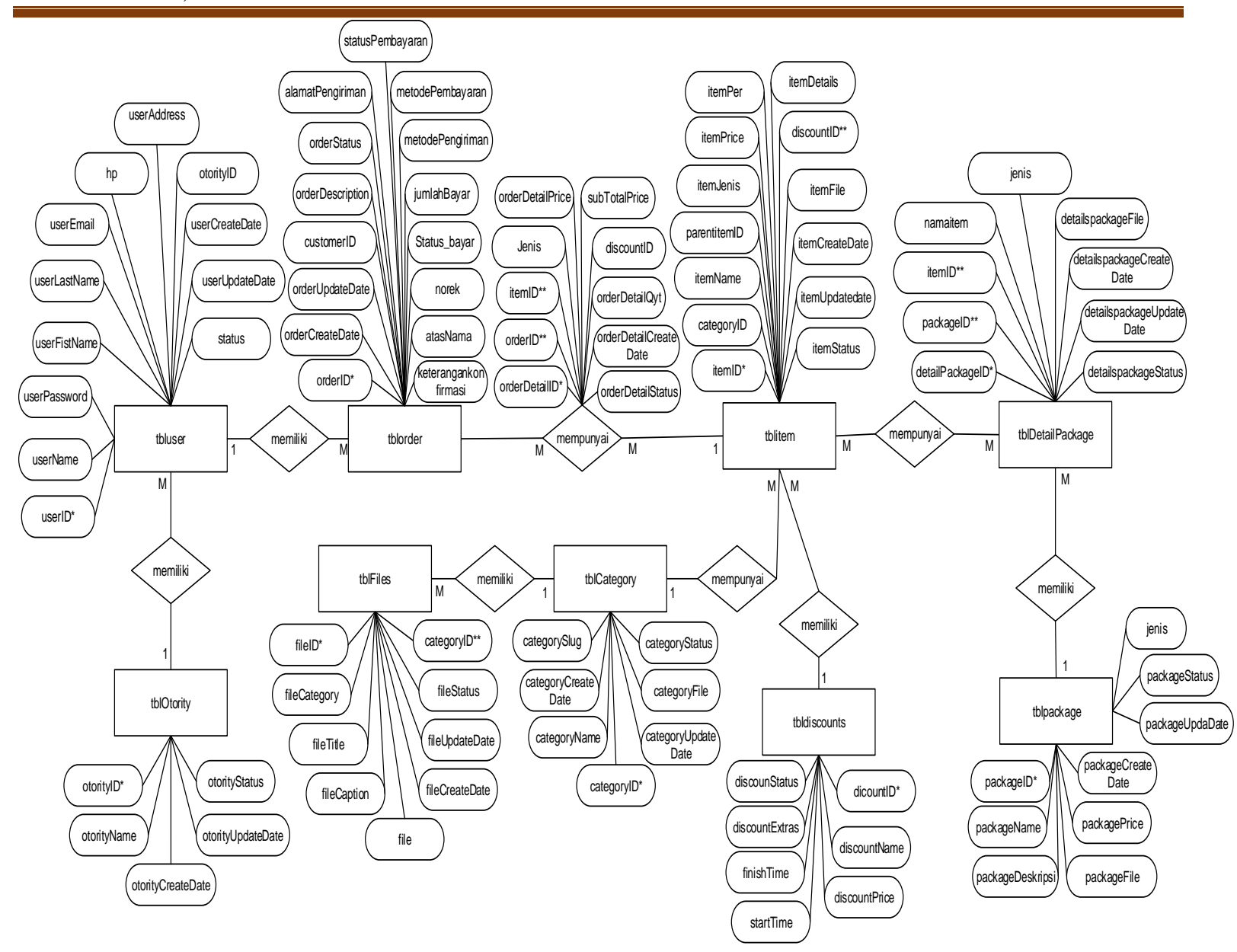

Gambar 1. Entity Relationship Diagram Diamond Wedding

\section{HASIL DAN PEMBAHASAN}

Berikut adalah hasil perancagan dengan UML (Unified Modeling Language) meliputi diagram Use Case dan diagram aktivitas.

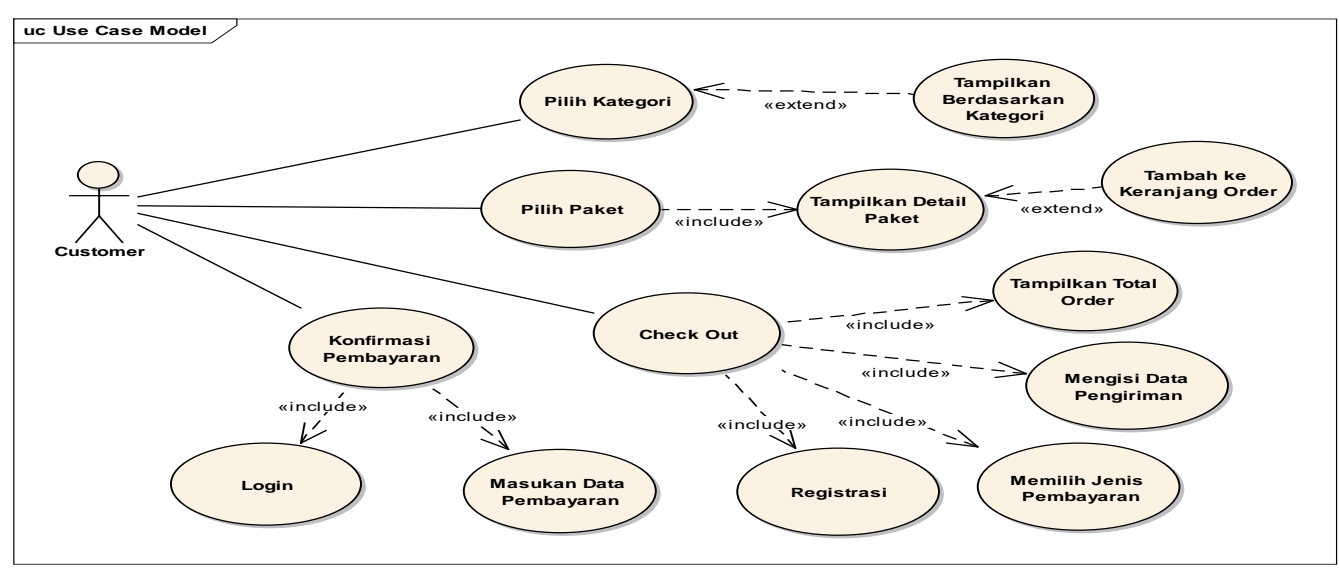

Gambar 2. Deskripsi Use Case Diagram Halaman Customer 


\section{Tabel 1. Deskripsi Use Case Diagram Halaman Customer}

\begin{tabular}{|l|l|}
\hline Use Case Name & Pemesanan Paket Pernikahan secara online \\
\hline Requirement & A1-A4 \\
\hline & $\begin{array}{l}\text { Member dapat melakukan pemesanan, pembayaran secara online yang } \\
\text { tersedia pada halaman website }\end{array}$ \\
\hline Pre-Condition & Member telah terdaftar \\
\hline Post Condition & Member melakukan pemesanan dan pembayaran secara online \\
\hline Failed end Condition & Member membatalkan secara online \\
\hline Main Flow/ Basic Path & $1 . \quad$ Member dapat melihat melihat isi dari paket-paket pernikahan yang \\
& ditawarkan \\
& 2. Member dapat melakukan konsultasi sebelum memilih paket pernikahan. \\
& $3 . \quad$ Member dapat melakukan order atau pemesanan. \\
& $4 . \quad$ Member melakukan pembayaran dan menerima bukti pembayaran. \\
\hline Invariant & - \\
\hline
\end{tabular}

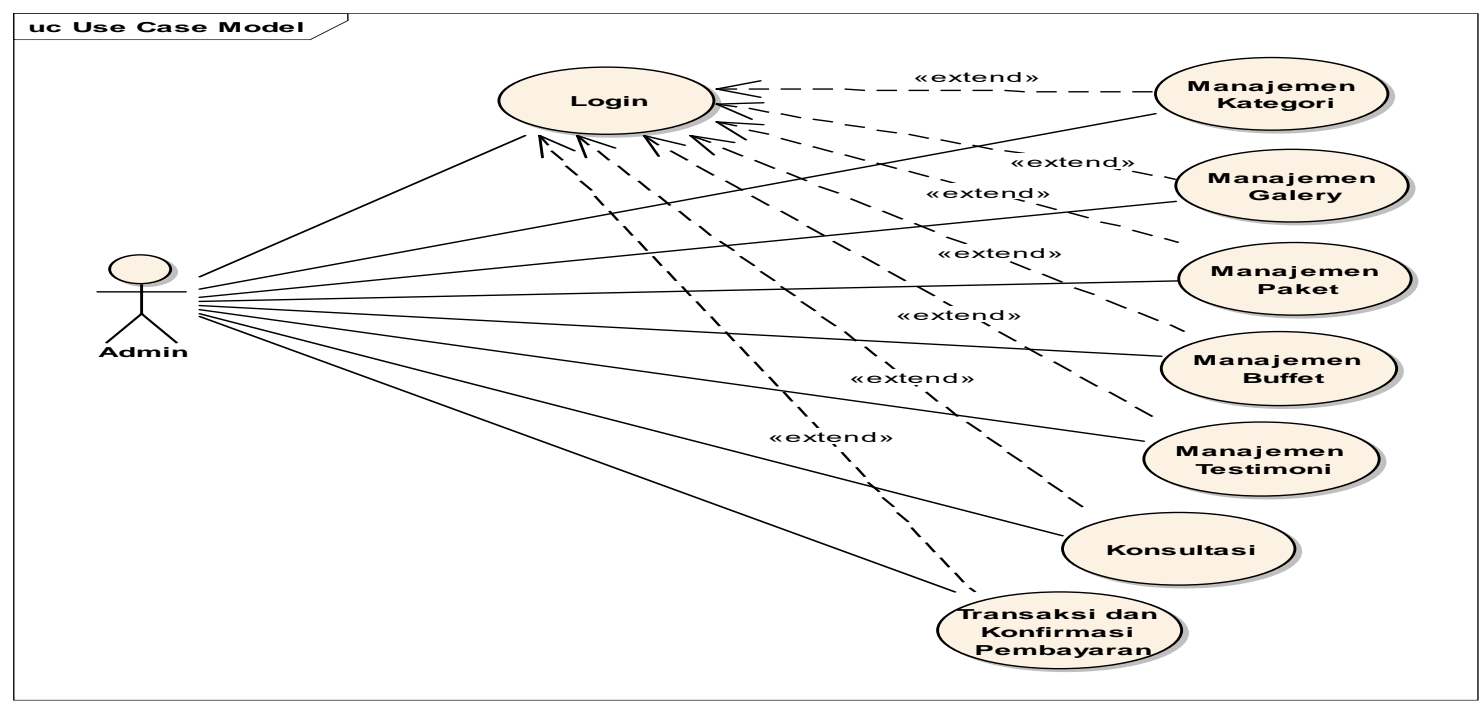

\section{Gambar 3. Perancangan Use Case Diagram Diamond Wedding Halaman Admin}

Tabel 2. Deskripsi Use Case Diagram Halaman Admin

\begin{tabular}{|l|l|}
\hline Use Case Name & Mengelola data pada website \\
\hline Requirement & C1-C7 \\
\hline Goal & admin dapat menampilkan data transaksi dan struk pembayaran \\
\hline Pre-Condition & Mengelola situs web \\
\hline Post Condition & manajemen data transaksi dan konfirmasi pembayaran dapat ditampilkan \\
\hline Failed end Condition & Laporan tidak dapat ditampilkan \\
\hline Main Flow/ Basic Path & 1. Admin mengelola data manajemen Kategori \\
& 2. Admin mengelola data manajemen Galery \\
& 3. Admin mengelola data manajemen Paket \\
& 4. Admin mengelola data manajemen Buffet \\
& 5. Admin mengelola data manajemen Testimoni \\
& 6. Admin mengelola data Konsultasi \\
& 7. Admin mengelola data Transaksi dan Konfirmasi Pembayaran \\
\hline Invariant & Menampilkan data manajement , List order dan Data transaksi konfirmasi \\
& pembayaran \\
\hline
\end{tabular}

Adapun diagram aktivitas Pilih Paket Pernikahan yang diusulkan seperti dibawah ini: 


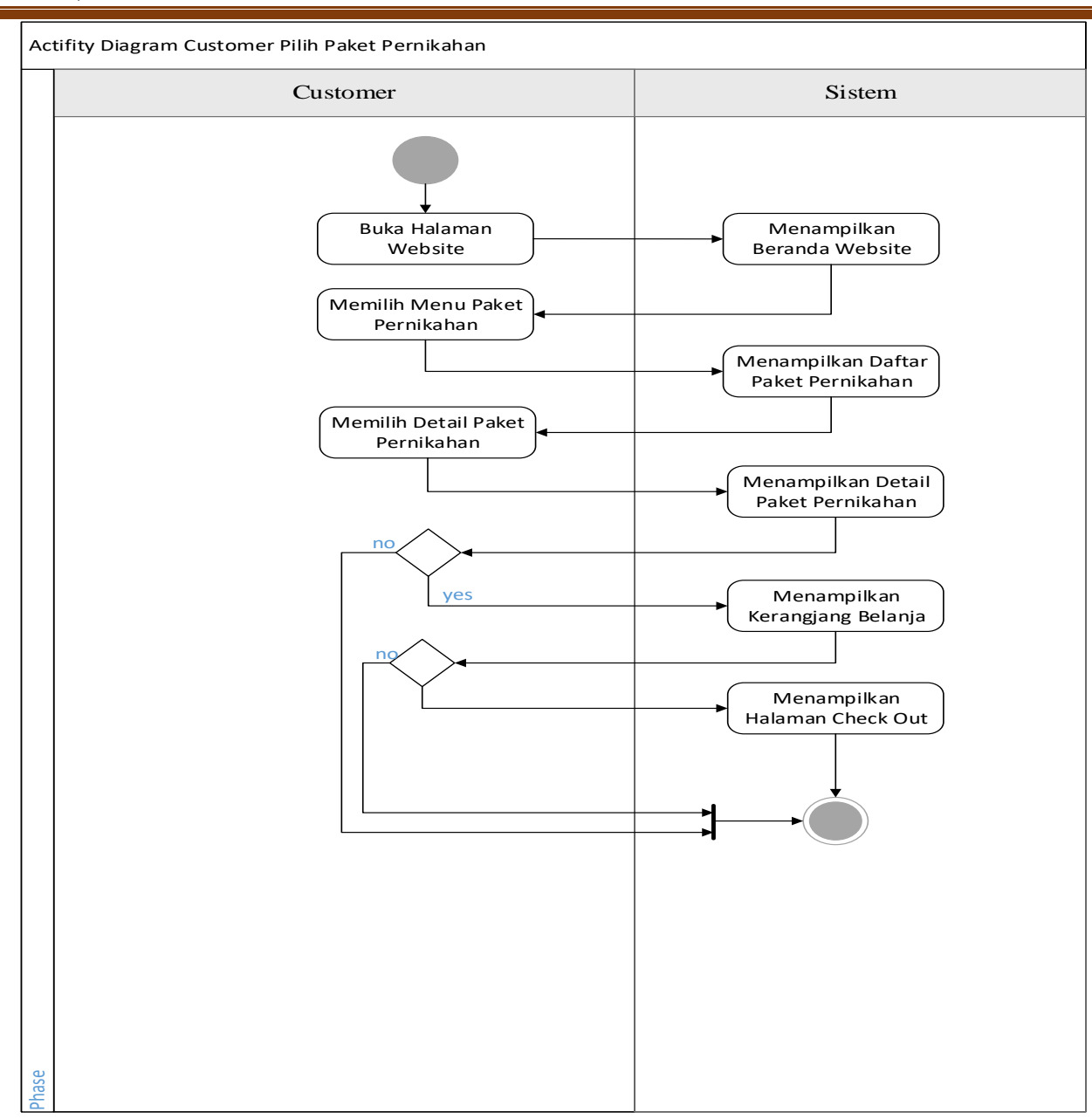

Gambar 4. Activity Diagram Customer Pilih Paket Pernikahan

Adapun diagram activity diagram konsultasi yang diusulkan seperti dibawah ini : 


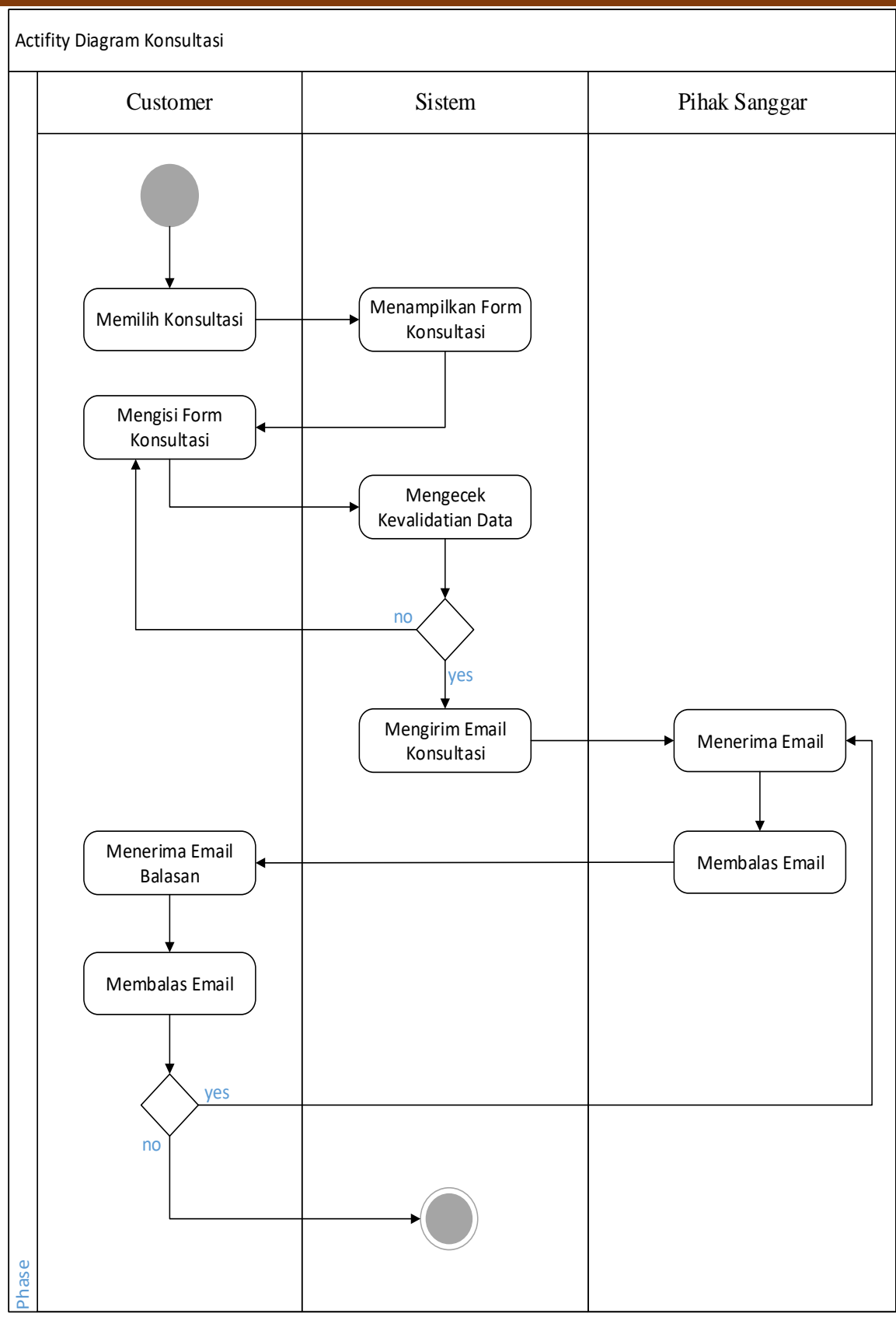

Gambar 5. Activity Diagram Konsultasi

Adapun diagram aktivitas Pendaftaran yang diusulkan seperti dibawah ini : 


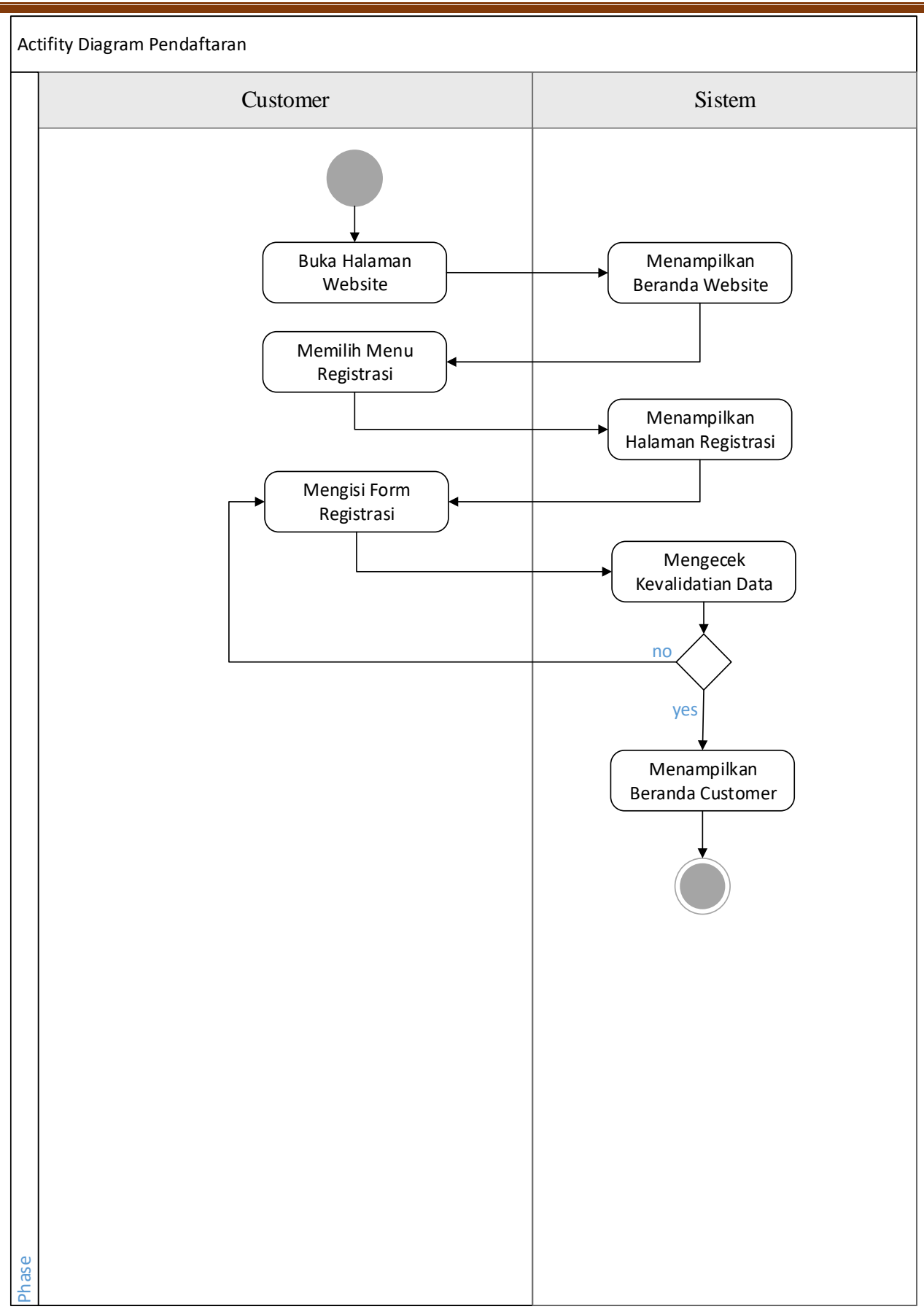

Gambar 6. Activity Diagram Pendaftaran

Adapun diagram activity diagram Login Customer yang diusulkan seperti di bawah ini: 


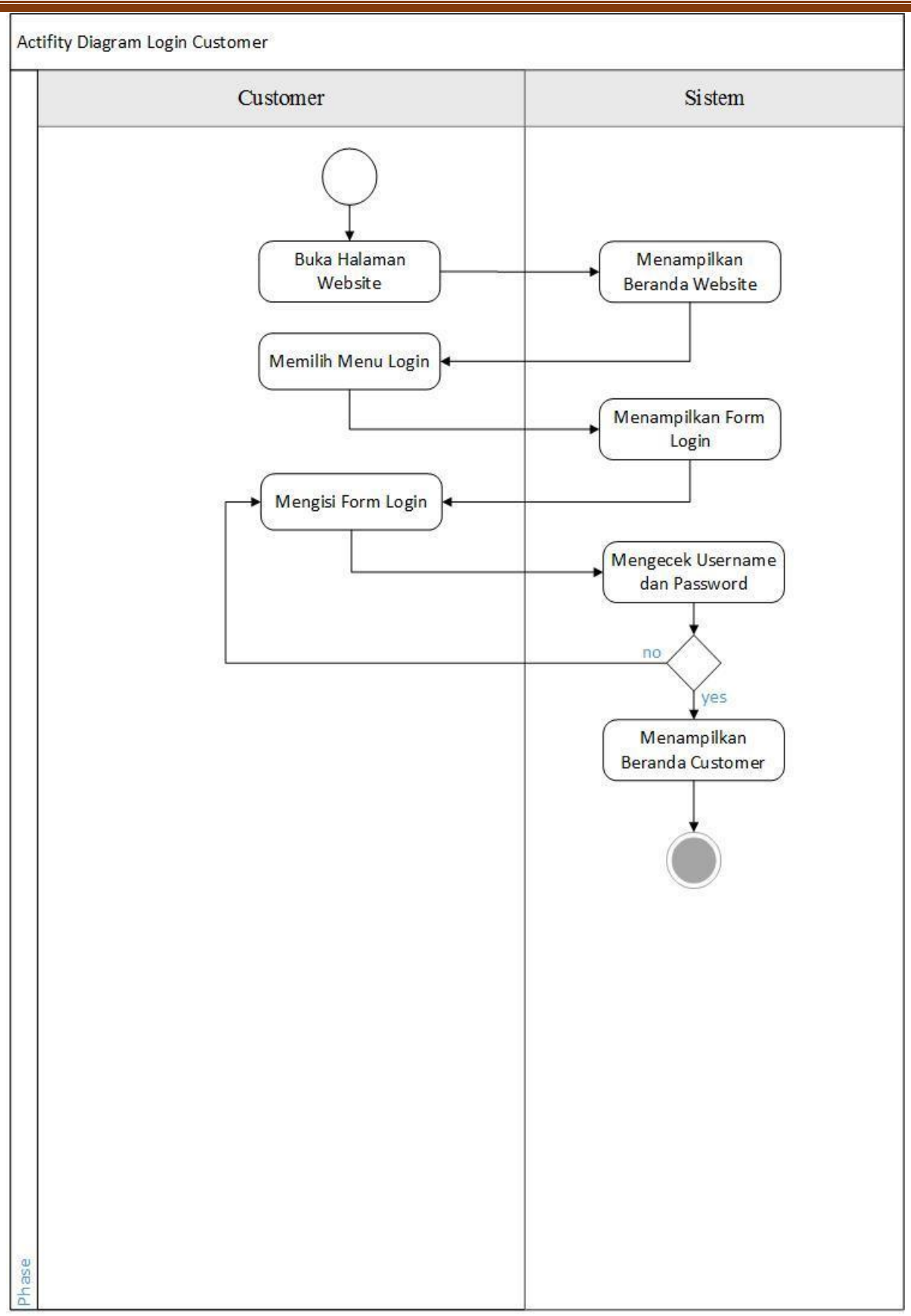

Gambar 7. Activity Diagram Login Customer

Adapun diagram aktivitas Transaksi dan Konfirmasi Pembayaran yang diusulkan seperti dibawah ini: 


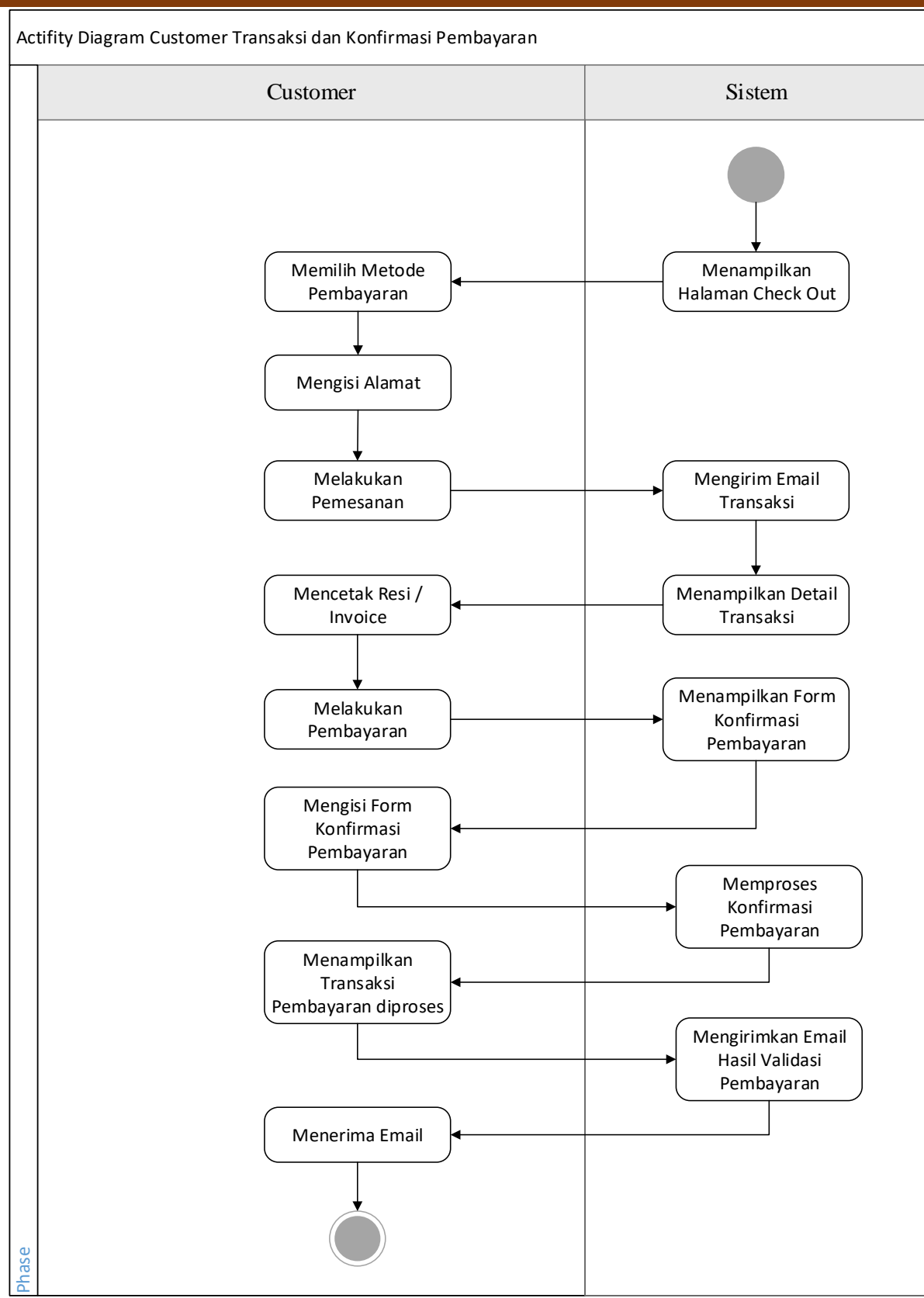

Gambar 8. Activity Diagram Transaksi dan Konfirmasi Pembayaran 


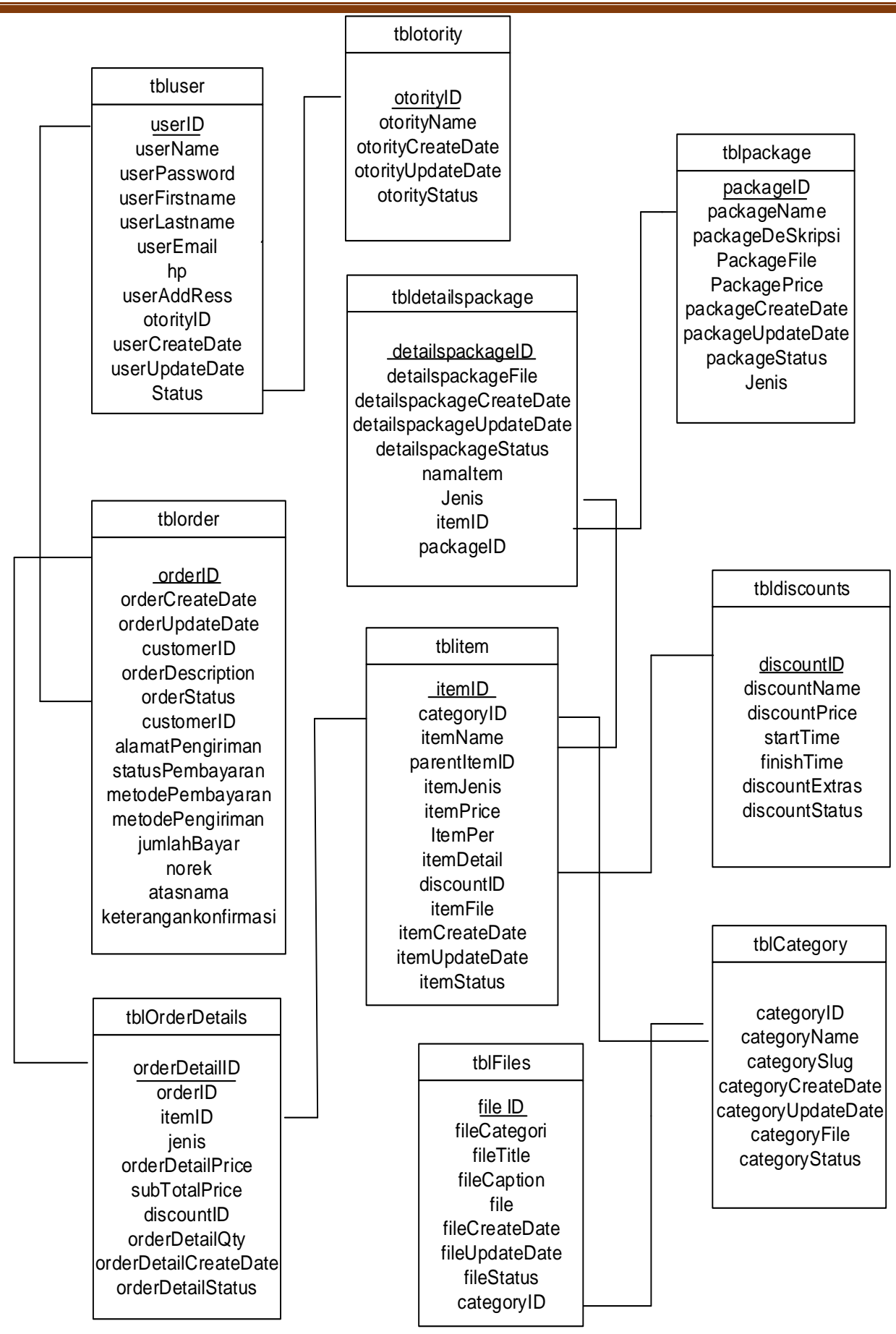

Gambar 9. Logical Record Structure Diamond Wedding 


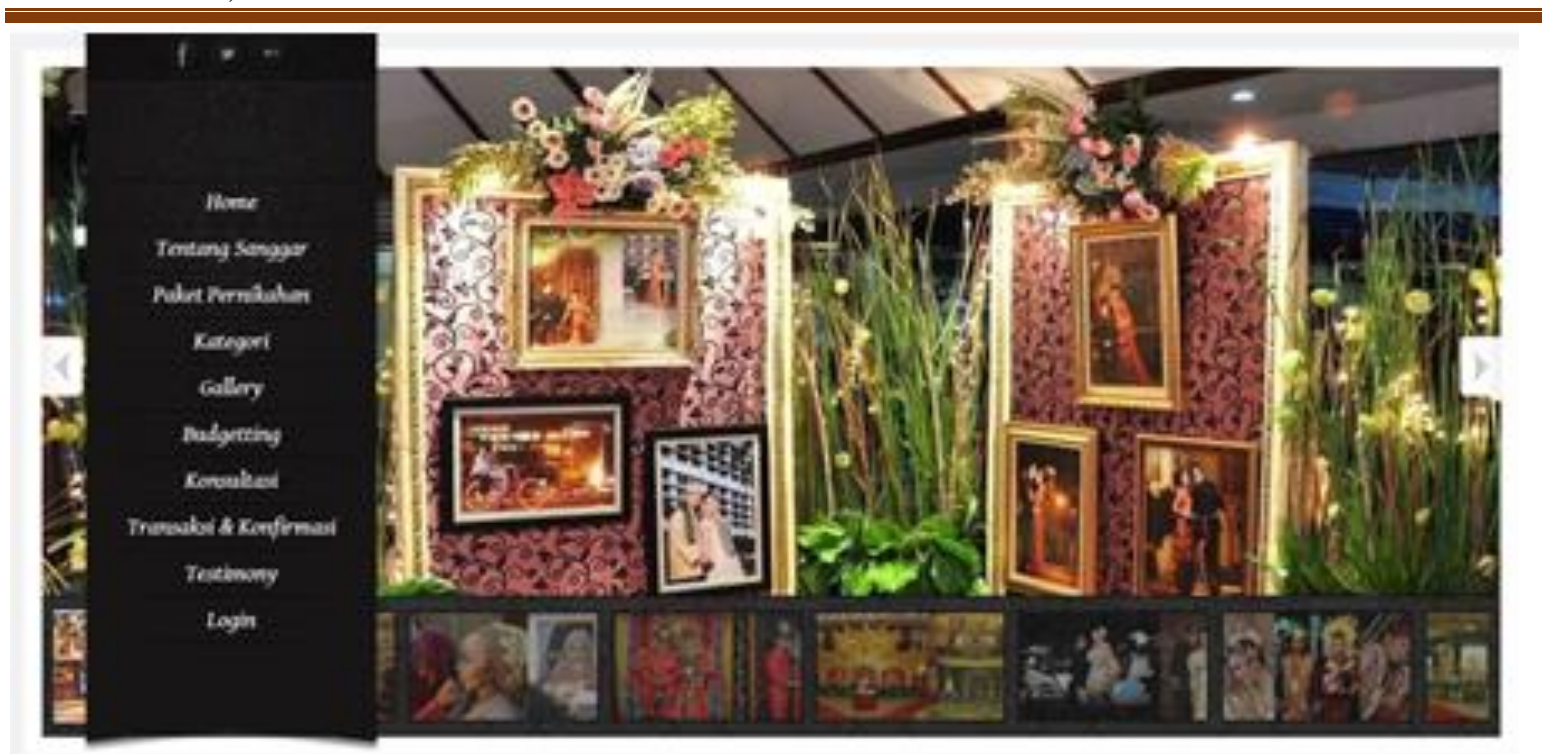

Gambar 10. Tampilan Halaman Customer
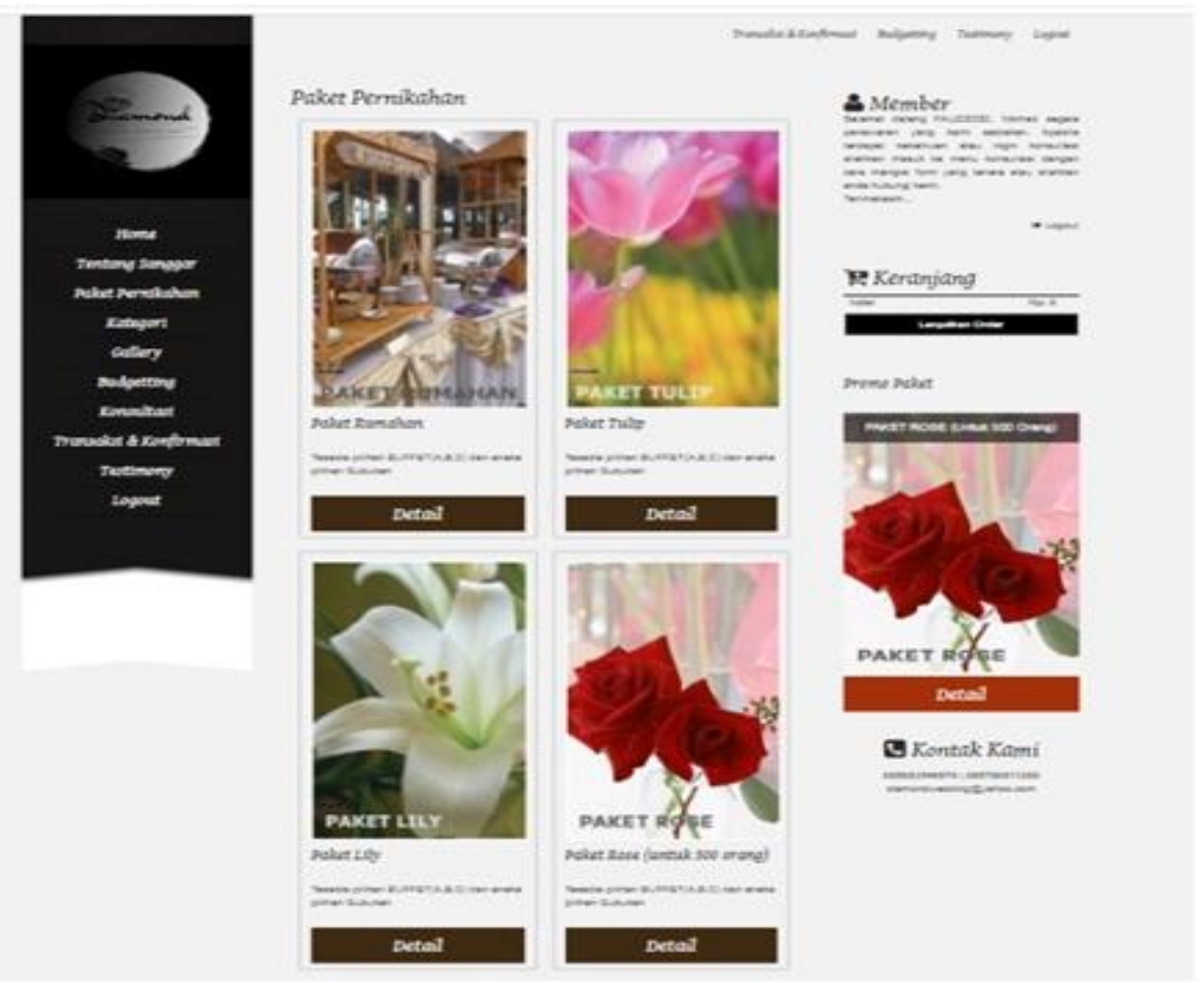

Gambar 11. Tampilan Paket Pernikahan 


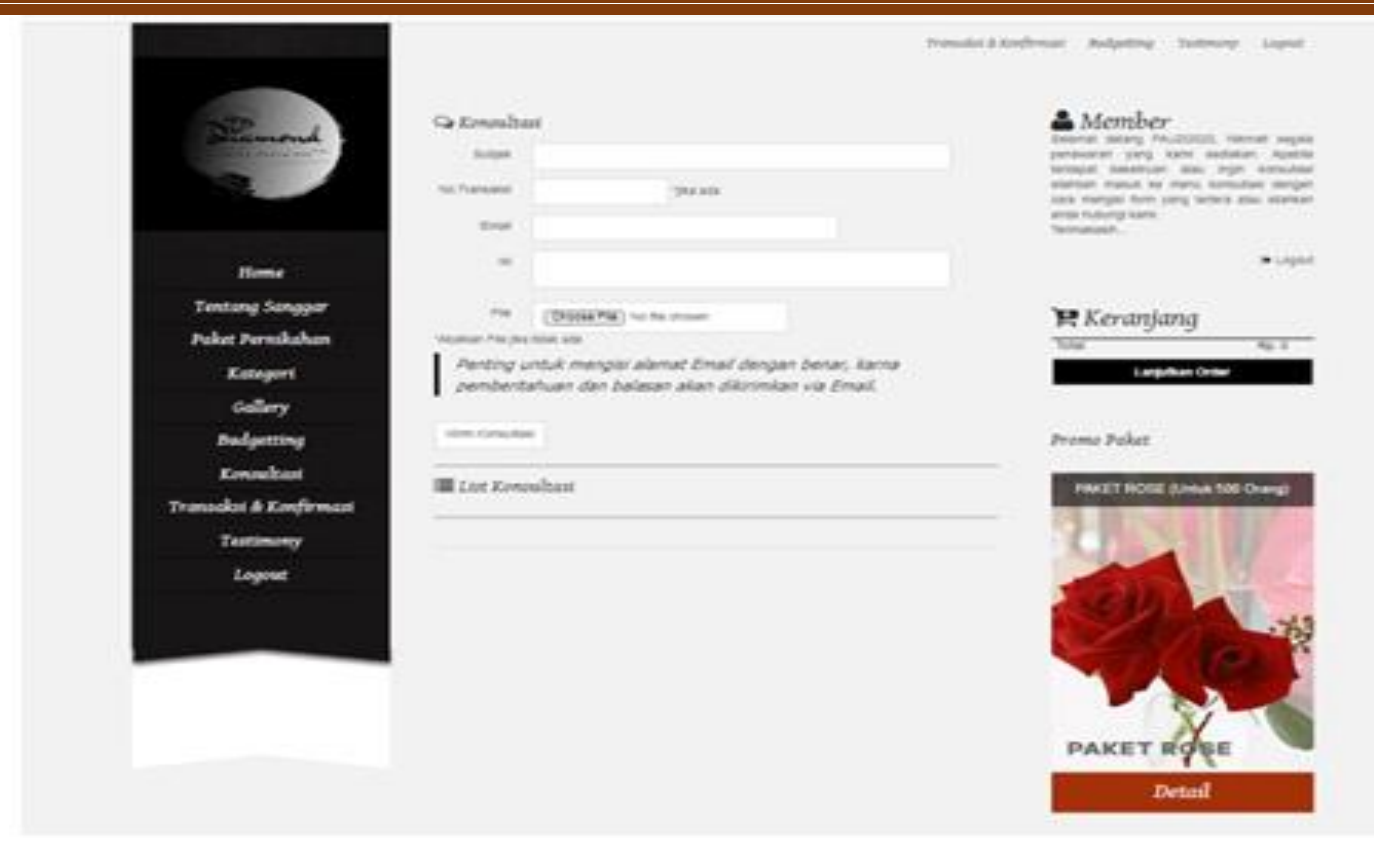

Gambar 12 . Tampilan Konsultasi

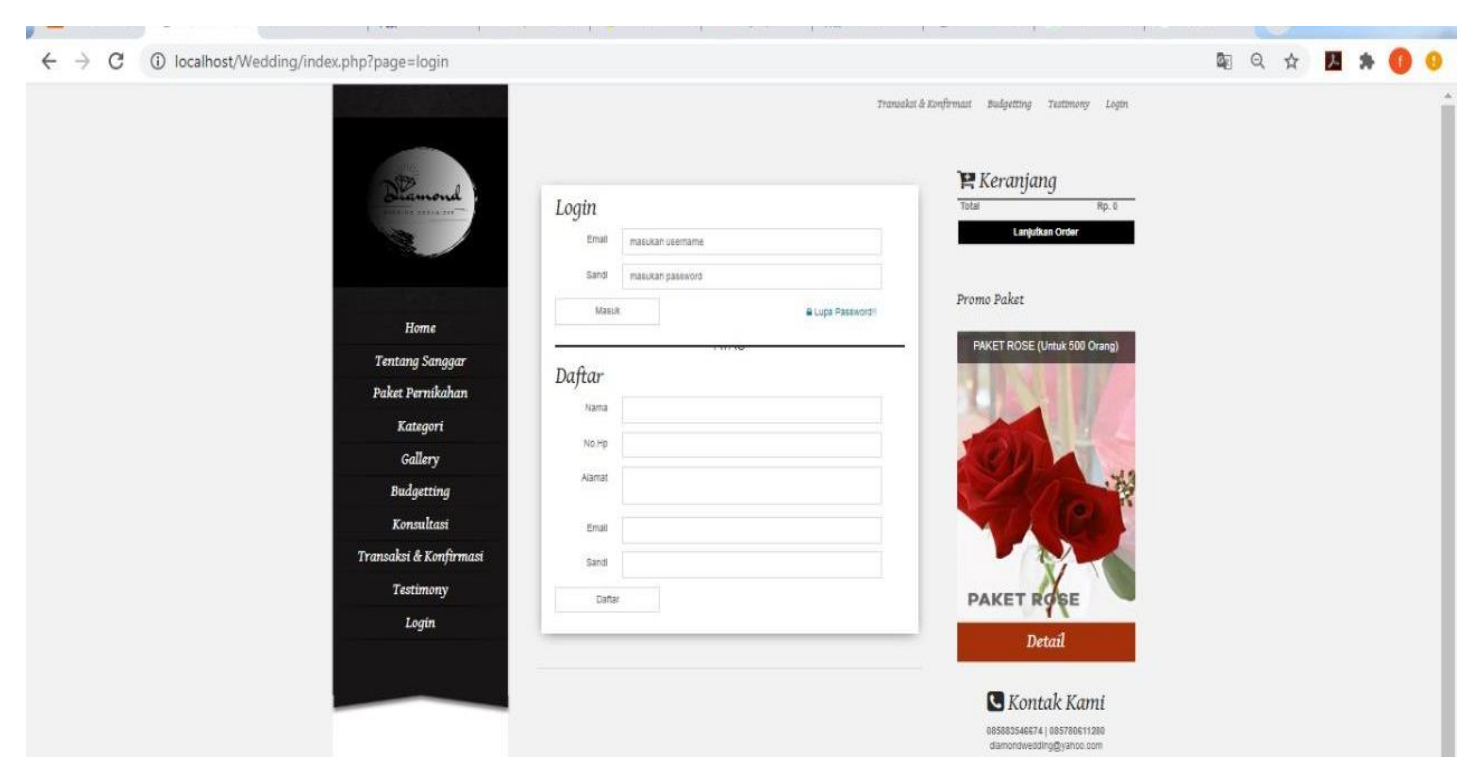

Gambar 13. Tampilan Pendaftaran Customer 


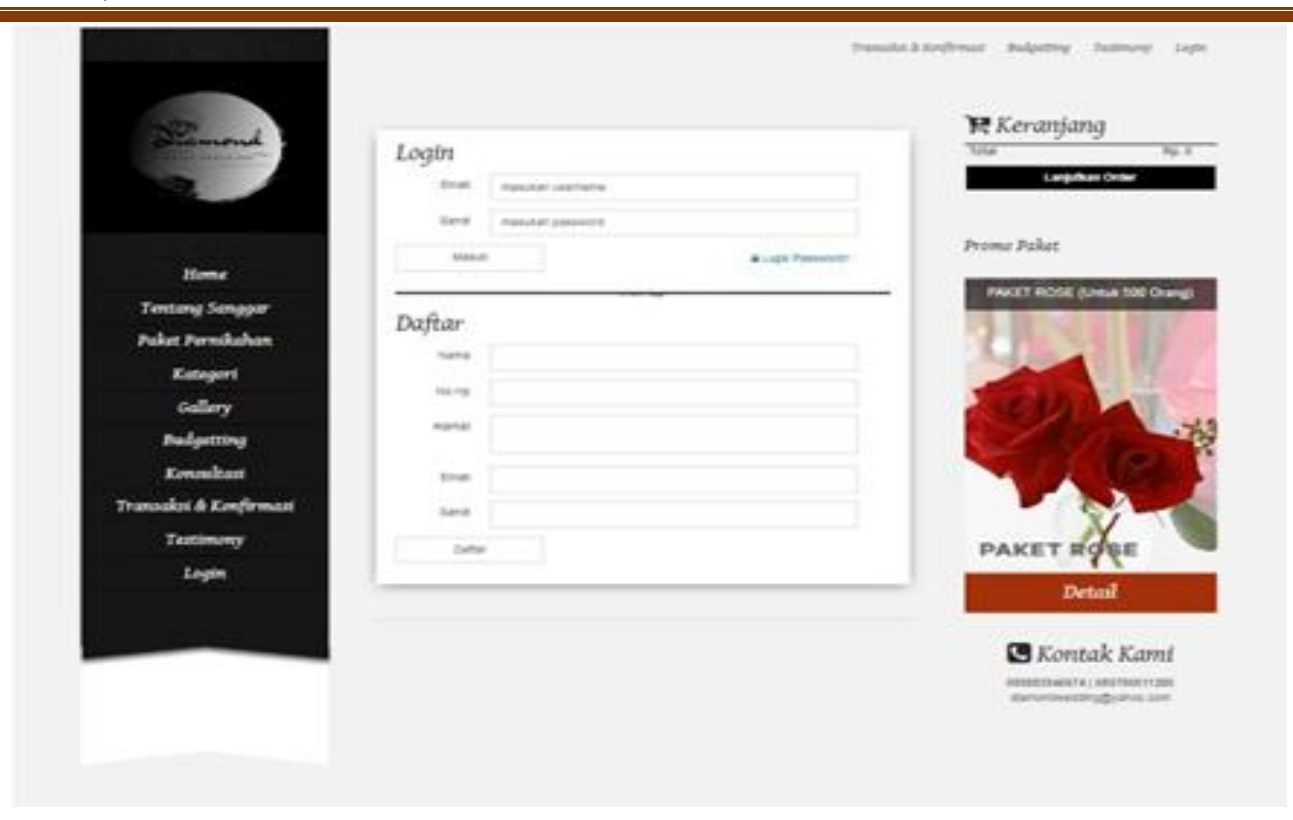

Gambar 14. Tampilan Login Customer

\section{KESIMPULAN DAN REKOMENDASI}

Dari perancangan program sistem Informasi Pemesanan Paket Pernikahan berbasis web dapat ditarik kesimpulan sebagai berikut:

1. Program Pemesanan Paket Pernikahan pada Diamond Wedding dapat membantu calon pengantin dalam mempersiapkan acara pernikahan secara real time online karena sudah menggunakan website dalam pemesanannya

2. Program pemesanan paket pernikahan ini dilengkapi dengan adanya from transaksi dan konsultasi akan mempermudah customer dalam melakukan proses transaksi pemesanan, sehingga tidak akan menyita waktu yang lama.

3. Dengan adanya paket-paket pernikahan yang tersedia pada Diamond wedding, sanggat membantu customer dalam menentukan pilihan paket yang akan digunakan pada acara pernikahan.

Dengan selesainya program Perancangan Sistem Informasi Pemesanan Paket Pernikahan Berbasis web pada Diamond Wedding ini, ada beberapa saran untuk ditanggapi oleh pihak yang berkepentingan, sebagai berikut:

1. Isi situs web seharusnya di maintance oleh admin secara berkala sesuai dengan perkembangan yang terjadi, guna memberikan informasi yang akurat. 
2. Pengembangan program pemesanan paket pernikahan perlu ditingkatkan agar kinerja dapat berjalan maksimal dan perlu dilakukan perawatan program untuk mencegah terjadinya error.

3. Dengan adanya program pemesanan paket pernikahan pada Diamond Wedding secara online dapat mendukung pengembangan program pernikahan, dan memudahkan calon pengantin mendapatkan informasi mengenai pemesanan paket pernikahan. Direkomendasikan agar selanjutnya dikembangkan dengan model komunikasi yang lebih cepat seperti fitur chatting dan sebagainya, agar dapat tercipta komunikasi antara pihak sanggar dan customer dengan bantuan pemesanan paket pernikahan secara menyeluruh.

\section{REFERENSI}

Ayu, F. and Fitri, N. (2019) 'Perancangan Sistem Informasi Pemesanan Wedding', IntraTech.

Bestari, C. A. (2020) 'Manajemen Perencanaan Usaha Pada Pelayanan Di Putri Wedding Organizer', e-Journal, 21(1), pp. 1-9.

Clivan, T., Sugiarso, B. A. and Sinsuw, A. A. E. (2019) 'Aplikasi Website Perpustakaan Berbasis QR- Code', Teknik Informatika, 14(1), pp. 1-8.

Fuad, H., Budiman, A. and Kurniasari, D. (2018) 'Perancangan Sistem Informasi Pemesanan Paket Pernikahan Berbasis Web Study Kasus Di Wedding Organizer PJ Management', Sisfotek Global, 8(2), pp. 136-141.

Karlina (2020) 'Rancang Bangun Sistem Pengadaan Jasa Wedding', Jurnal Riset dan Aplikasi Mahasiswa Informatika, 01(02), pp. 253-258.

Lestanti, S. and Susana, A. D. (2016) 'Sistem Pengarsipan Dokumen Guru Dan Pegawai Menggunakan Metode Mixture Modelling Berbasis Web', Jurnal Antivirus, 10(2), pp. 69-77.

Luluk Nindy Rizky Amanda and Ratna, S. (2017) 'E-Commerce Karya Seni Pada Borneo Art Enthusiast 1', Technologia, 8(4), pp. 284-291.

Lutfi, A. (2017) 'Sistem Informasi Akademik Madrasah Aliyah Salafiyah Syafi'Iyah Menggunakan Php Dan Mysq', AiTech, 3(2), pp. 104-112.

Nugraha, A. and Anita Octasia (2016) 'Sistem Informasi Penjualan Kaos Berbasis Web Pada Distro Sickness Berbasis E - Commerce', SNIPTEK, pp. 299-302.

Pasaribu, J. S. (2017) 'Penerapan Framework YII Pada Pembangunan', jurnal ilmiah teknologi informasi terapan, III(2), pp. 154-163. 
Permata, D., Tasrif, Ee. and Dewi, I. P. (2018) 'Perancagan Sistem Informasi Pemesanan Wedding Organizer di Kota Padang', Jurnal Vokasional Teknik Elektronika Dan Informatika, 6(1), pp. 2-7.

Rochman, A., Sidik, A. and Nazahah, N. (2018) 'Perancangan Sistem Informasi Administrasi Pembayaran SPP Siswa Berbasis Web di SMK Al - Amanah', Sisfotek Global, 8(1).

Taniah, A. W. and Harjunawati, S. (2017) 'Perancangan Sistem Informasi Transaksi Penyewaan', Ilmu Pengetahuan Dan Teknologi Komputer, 3(2527-4864), pp. 5964.

Ummah, L. D. (2018) 'Rancang Bangun E-Commerce Pada Toko Kerudung Nuri Collection Berbasis Customer Relationship Management', Nuansa Informatika, 12, pp. 10-17.

Witanto, R. and Solihin, H. H. (2016) 'Perancangan Sistem Informasi Penerimaan Siswa Baru Berbasis Web (Studi Kasus: Smp Plus Babussalam Bandung)', Jurnal Teknologi Informasi dan Elektronika (INFOTRONIK), 1(1), pp. 54-63. 